unsettled. However, the data show that frequency shifts are very small for words which were common to both counts. If shifts in the frequencies of the missing words were the same as shifts in the frequencies of the common words, then it would be expected that little error would be introduced through the continued use of the scale.

\section{REFERENCES}

BO WEN, J. H. Familiarity scale values for 420 nouns in twelve combinations of frequency of occurrence and conceptual ategorization. Psychological Reports. 1969,25 , Monograph Supplement 3.

CARROLL, J. B. On sampling from a lognormal model of word-frequency distribution. In $\mathbf{H}$. Kučera and $\mathbf{W}$. $\mathbf{N}$. Francis (Eds.), Computational analysis of present-day American English. Providence: Brown University, 1967.
CARROLL, J. B. A rationale for an asymptotic lognormal form of word-frequency distributions. Research Bulletin RB-69-90, 1969, Educational Testing Service, Princeton, N.J.

KUĆERA, H., \& FRANCIS, W. N Computational analysis of present-day American English. Providence: Brown University, 1967.

THORNDIKE, E. L., \& LORGE, I. The teacher's word book of 30,000 words. New York: Bureau of Publications, Teachers College, Columbia University, 1944.

WEBSTER'S Third New International Dictionary. (4th ed., unabridged) Springfield, Mass: Merriam, 1967.

\section{NOTE}

1. The high positive $Y$-intercepts are the result of the fact that the functions are plotted in the third and fourth quadrants of a geometric space and have positive slopes.

\title{
Learning mixed social structures
}

\author{
NANCY M. HENLEY \\ University of Maryland, Baltimore County, Md. 21228 \\ and \\ ROBERT B. HORSFALL* \\ The Johns Hopkins University, Baltimore, Md. 21218
}

The goodness of figure of social structures formed of mixed symmetric and assymmetric relations was predicted by a formula taking into account both linearity and balance. The formula was tested in a learning experiment in which 71 Ss learned one of eight six-man hypothetical structures, varying in predicted goodness of figure. Mean errors were 36.63 among the "good" figures and 54.98 among the "poor" figures; in an analysis of variance, the Fratio for the dichotomous goodness of figure variable was 33.42 ( $\mathrm{df}=1,273, \mathrm{p}<.001$ ). The product-moment correlation between predicted goodness and learning errors was -.67 .

It would be a fine world if social psychologists were able to predict the amount of strain inherent in any social situation, given the relationships among the persons involved. Such predictability would rest largely on a knowledge of the amount of "structural strain" characteristic of different social situations, i.e., strain resulting from imbalances or inconsistencies in the network of relations. Heider's $(1946,1958)$ balance theory, especially as generalized by Cartwright \& Harary (1956), has attempted just this sort of prediction and has been largly supported by experimental verification (Jordan, 1953; Burdick \& Burnes, 1958; Kogan \& Tagiuri, 1958; Morrissette, 1958; Davol, 1959; Zajonc \& Burnstein, 1965; De Soto, Henley, \& London, 1968). A second approach to the prediction of

* Now at Simon Fraser University. Burnaby, B.C., Canada. structural strain is that taken by those (generally sociologists) concerned with status congruency or crystallization (Benoit-Smullyan, 1944). Numerous studies have shown strain to be associated with incongruency among the various statuses of an individual in a group (e.g., Adams, 1953; Homans, 1953; Lenski, 1954; Exline \& Ziller, 1959; Jackson, 1962; Burnstein \& Zajonc, 1965; Kasl \& Cobb, 1967). Still another approach has been taken by De Soto $(1960,1961)$, who has brought forward evidence for the existence of ordering, grouping, and symmetry schemas which affect people's cognitions of social groups, strain being produced when the schemas are violated (Wunderlich, Youniss, \& De Soto, 1962; Kuethe \& De Soto, 1964; De Soto, London, \& Handel, 1965; Mosher, 1967; De Soto, Henley, \& London, 1968). De Soto has suggested the "predilection for single orderings [1961]" to account for the effects of status incongruency, and "conceptual good figure [De Soto \& Albrecht, 1968]" as a concept unifying his approach and that of Heider.

Continuing in the latter tradition, Henley, Horsfall, \& De Soto (1969) suggest a graph theoretical approach to assessing conceptual good figure in tournaments (structures formed completely of asymmetric relations). ${ }^{1}$ This approach is extended to structures formed of mixed symmetric and asymmetric relations, with good predictive power. Because the present paper builds on the ideas reported in that study, it will help to summarize their predictions and findings. Those authors first used the Kendall \& Smith (1940) coefficient of consistency, 1 (actual cyclic triples/maximum possible cyclic triples), as an index of "linearity" in tournaments, predicting an increase in errors as linearity decreases. This measure was found to correlate well $(r=-.90)$ with errors made in learning hypothetical social structures. They next applied a modification of the measure to a reanalysis of earlier results reported by De Soto (1960); the modification was made so that linearity could be measured in structures which are incomplete and/or formed of mixed symmetric and asymmetric relations. Again, the predictive power of the index was high $(r=-.95)$. Horsfall \& Henley (1969) later applied the modified measure in a study of strain and probability ratings of triadic structures formed of mixed relations, but found high strain and low probability more closely associated with the presence of a single negative relation in a structure than with the presence of a single cycle. They concluded that the failure of the measure to account for rated strain and probability might be due either to differences in the experimental tasks (i.e., learning vs rating) or to the fact that "people might be able to discern and recall well interpersonal relationships in structures which they would find unpleasant or which are unlikely to occur [p. 187]."

The present study was undertaken in order to resolve certain questions resulting from the foregoing research on mixed structures. First, De Soto's structures were composed of four men and were largely incomplete, with few actual relations to learn; the Horsfall and Henley structures were complete but triadic, allowing only a division into "good" and "bad" figure. Does the modified coefficient of consistency predict well for large, complete, and more complex mixed structures? Second, what effect will negative relations have in learning mixed structures; specifically, will the mixed triads with a single negative line 

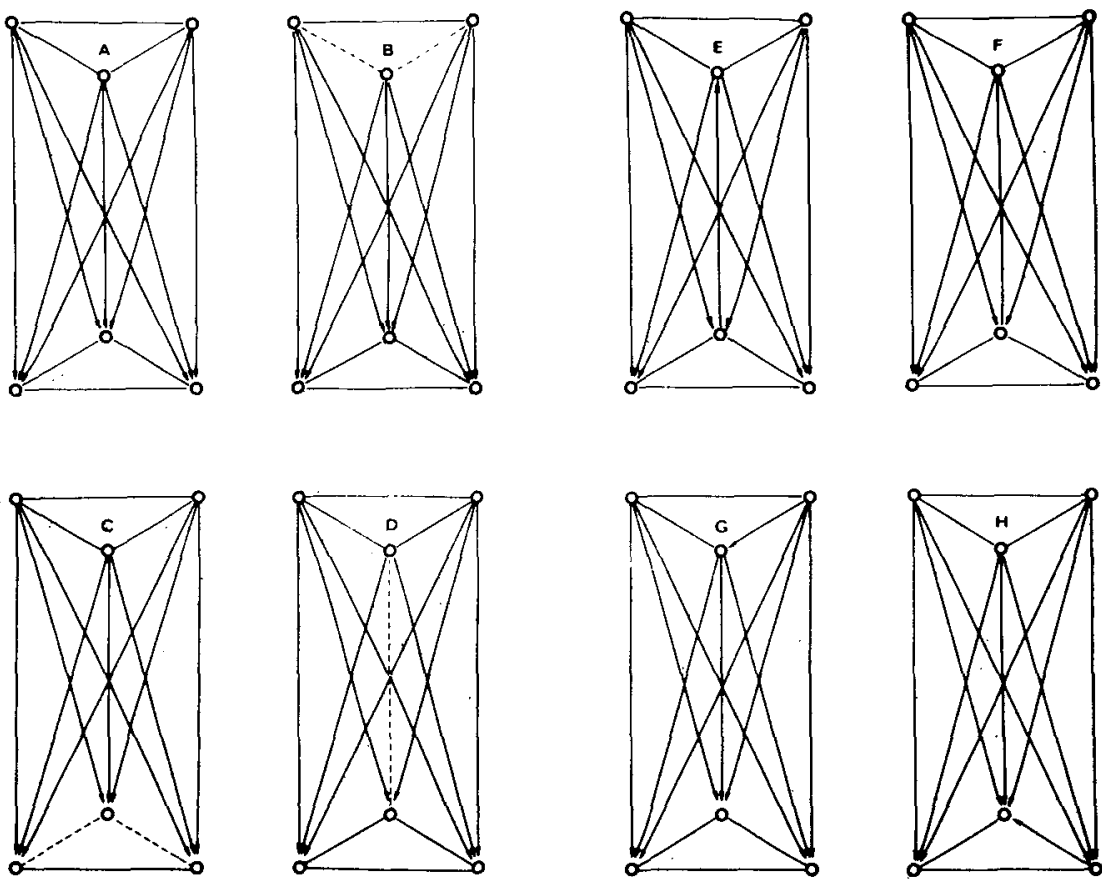

Fig. 1. Structures used in this experiment. Circles represent men; solid lines, friendship; negative lines, enmity; arrows, influence (arrow points to influenced person).

prove to be error-producing (as the Horsfall and Henley study suggests)? In the present study, Ss were asked to learn all the relationships within completely connected six-man social structures formed of mixed symmetric and asymmetric relations, and their errors in learning the structures were analyzed. The eight structures used are shown in Fig. 1. (It should be noted that imbalance is not a factor in any of the structures.)

INDEX OF GOOD FIGURE

Since the coefficient of consistency (in original and modified form) is based upon the maximum cycles found in a tournament of a given number of points, it is inappropriate to apply it to mixed structures, which can have more cycles than a tournament of the same size. Furthermore, in considering all possible mixed structures, the concept of balance should be taken into account: unbalanced triples must be recognized as detracting from good figure. The revisions necessary to this consideration lead to a new index of good figure (GF) which includes both the concepts of linearity and balance. For this index, good figure is violated by either unidirectional three cycles or unbalanced triples. Unidirectional three cycles are triples in which at least one relation is directed, and there exists a cycle through the relations. (A cycle may flow through positive, but not through negative, relations.)
Unbalanced triples are defined as those formed of all symmetric relations, with one or three relations negative. The index may be defined as $\mathrm{GF}=1$ [(total unidirectional 3 cycles + total unbalanced triples)/maximum possible triples]. Maximum possible triples for a structure of $p$ points is, of course, obtained by combinatorial computation, the formula being structure of Fig. 1 is given in Table 1 . METHOD

Male and female undergraduate $S$ were run in two groups, with each of the 71 Ss serving in only one condition (i.e., learning a single structure). There were 8-10 $\mathrm{Ss}$ in each condition.

Printed materials were used, in a procedure similar to that described in De Soto, Henley, \& London (1968) and Henley, Horsfall, \& De Soto (1969). There were four learning trials (information sheets alternating with response sheets) presented in eight-page booklets. Ss read the information about the structure, then (on E's signal) turned the page and gave the same information back, in a different order. For each condition there were two versions of the structure presented, the positions held by persons in the structure being varied on the page in the different versions. Care was taken not to let order of presentation suggest any ordering in the hypothetical structure. Each structure consisted of six men $[p(p-1)(p-2)] / 6$. GF for each joined by the relations "is a friend of," "is an enemy of," "influences," and "is influenced by." A typical set of information (for Structure F) is shown below:

$\begin{array}{ll}\begin{array}{l}\text { Ned is a friend of: } \\ \text { Ned is an enemy of: } \\ \text { Ned influences: } \\ \text { Ned is influenced by: }\end{array} & \begin{array}{l}\text { Pat, Joe } \\ \text { no one } \\ \text { Sam, Do } \\ \text { Ben }\end{array} \\ \text { Joe is a friend of: } & \begin{array}{l}\text { Don, Pat, } \\ \text { Ned } \\ \text { no one }\end{array} \\ \text { Joe is an enemy of: } \\ \text { Joe influences: } \\ \text { Joe is influenced by: Sam, Ben }\end{array}$

and so on for the rest of the men in the structure. The answer sheet for this set of information was as follows:

Ned is a friend of: Sam, Don, Ben, Pat, Joe

Ned is an enemy of: Sam, Don,

Ned influences: Sam, Don, Ben, Pat, Joe

Ned is influenced by: Sam, Don, Ben, Pat, Joe

and so on, for all six persons in the structure. Ss circled the appropriate names on the answer sheet.

The printed instructions, read aloud by $E$ as the $S$ s read them silently, requested the Ss to "learn about the relationships among a set of people. The relationships could refer to persons working together in an office, in a military organization, or in some other interpersonal situation." One and one-half minutes were allowed on each page.

In scoring the answer sheets, any wrongly specified relation, an omission, intrusion, or both, counted as a single error. Each of the six names had five different names listed after it, for a total of 30 possible errors on each trial.

\section{RESULTS}

Mean errors for each structure, summed over all four trials, are shown in Table 1. Errors decreased consistently over trials, mean errors for Trials 1-4 being, respectively, $19.25,12.85,8.27$, and 5.20. The correlation of GF with errors is -.67 $(\mathrm{N}=8$, significantly different from zero, $\mathrm{p}<.05$ ).

A Figure by Trials analysis of variance was performed, the figure variable being a dichotomous classification into good or poor figure (see Table 1). Individual structures were treated as a variable nested within the figure variable; Ss were a within-structure variable. Error terms were pooled when $F$ ratios for all $S$ interactions were found to be less than 1. The $F$ ratio for trials was $\mathbf{5 8 . 1 0}$ 
Table 1

Goodness of Figure (GF) and Mean Errors for Structures in Fis. 1, Divided into "Good" and "Poor" Figure

\begin{tabular}{|c|c|c|c|c|c|}
\hline \multicolumn{3}{|c|}{ Good Figure } & \multicolumn{3}{|c|}{ Poor Figure } \\
\hline $\begin{array}{l}\text { Struc- } \\
\text { ture }\end{array}$ & GF & $\begin{array}{c}\text { Mean Errors } \\
\text { Summed } \\
\text { Over Four } \\
\text { Trials }\end{array}$ & $\begin{array}{c}\text { Struc- } \\
\text { ture }\end{array}$ & $\mathbf{G F}$ & $\begin{array}{c}\text { Mean Errors } \\
\text { Summed } \\
\text { Over Four } \\
\text { Trials }\end{array}$ \\
\hline $\begin{array}{l}\mathbf{A} \\
\mathbf{B} \\
\mathbf{C} \\
\mathbf{D}\end{array}$ & $\begin{array}{l}1.00 \\
1.00 \\
1.00 \\
1.00\end{array}$ & $\begin{array}{l}24.33 \\
29.44 \\
38.50 \\
54.22\end{array}$ & $\begin{array}{l}\mathbf{E} \\
\mathbf{F} \\
\mathbf{G} \\
\mathbf{H}\end{array}$ & $\begin{array}{l}0.80 \\
0.80 \\
0.95 \\
0.95\end{array}$ & $\begin{array}{l}67.11 \\
51.44 \\
54.75 \\
46.62\end{array}$ \\
\hline $\begin{array}{l}\text { M tan } \\
\text { SD }\end{array}$ & 1.00 & $\begin{array}{l}36.63 \\
11.35\end{array}$ & $\begin{array}{l}\text { Mean } \\
\text { SD }\end{array}$ & 0.88 & $\begin{array}{r}54.98 \\
7.58\end{array}$ \\
\hline
\end{tabular}

( $d f=3,273)$; that for figure (good/poor), $33.42(\mathrm{df}=1,273)$; and that for structures within figure, 6.06 $(d f=6,273)$. All F ratios have a probability less than .001 .

The eight structures incorporated three pairwise comparisons of potentially strain-inducing deviations from ideal figure. In Structures $B$ and $C$, negative relations existed either in the upper stratum (B) or in the lower stratum (C); in Structures D and F, the symmetric relation between strata was either positive (F) or negative (D); in Structures $G$ and $H$, the asymmetric relation within a stratum was either in the upper (G) or lower (H) stratum. None of the differences in mean errors between the members of the pairs was significant by $t$ test.

\section{DISCUSSION}

The GF index predicted the learning of these complex mixed structures quite well. Considering the restricted range of GF $(0.80-1.00)$ used in this experiment, a correlation of -.67 seems sufficiently high. Use of structures with a broader range of variation in goodness of figure would be expected to result in a higher correlation. The restricted range was used here because the structures seemed complex enough with only minor departures from good figure, and previous testing suggested that increased complexity would make the learning task too difficult. The structures were specifically chosen to represent some simple cases of possible violations of "good figure": symmetry between strata $(D, F)$, asymmetry within a stratum $(G, H)$, negative relations within a stratum $(B, C)$, and reversed direction of an asymmetric relation between strata $(\mathrm{E})$.

With regard to these variations, it may be noted that both between-strata symmetry and within-stratum assymetry led to increased errors, though in Structure D the negative symmetric relation does not introduce cycles. The existence of negative relations within strata did not create excessive difficulty, though such difficulty might be predicted from the
Horsfall and Henley findings. It is interesting to note that of the four cycle-containing structures, the one structure whose cycles consist of two asymmetric and one symmetric relation; cycles in each of the three symmetric and one asymmetric relation. This suggests that the tendency toward linearity is more strongly evoked in cycles with more asymmetric relations; the total number of asymmetric relations in the full structure did not increase the tendency in this case, since Structures $\mathrm{G}$ and $\mathrm{H}$ both have more asymmetric relations than does Structure E.

It may further be noted that when Structure A is compared with D, E, F, $G$, or $H$, the differences are in a single relation only, but each of the latter structures has about double the errors that $A$ has associated with it. Such is the compelling rightness of a structure with both good figure and positivity.

The conclusions to be drawn from these results are that the degree of goodness of figure as measured by the formula given here does indeed predict the learning of complete complex structures formed of mixed symmetric and asymmetric relations, and that mixed triads with a single negative relation do not seriously reduce goodness of figure in a structure.

\section{REFERENCES}

ADAMS, $S$, Status congruency as a variable in small group performance. Social Forces, 1953, 32, 16-22.

BENOIT-SMULLYAN, E. Status, status types, and status interrelations. American Sociological Review, 1944, 9, 151-161.

BURDICK, H. A., \& BURNES, A. J. A test of "strain toward symmetry" theories Journal of Abnormal \& Social Psychology, 1958, 57, 367-370.

BURNSTEIN, E., \& ZAJONC, R. B. The effect of group success on the reduction of status incongruence in task-oriented groups. Sociometry, 1965, 28, 349-362. CARTWRIGHT, D., \& HARARY, F Structural balance: A generalization of Heider's theory. Psychological Review, $1956,63,277-293$.

DAVOL, S. H. An empirical test of structural balance in sociometric triads. Journal of Abnormal \& Social Psychology, 1959, 59, 393-398. producing most errors (E) is the only other structures consist of two
De SOTO, C. B. Learning a social structure. Journal of Abnormal \& Social Psychology, 1960,60, 417-421.

De SOTO, C. B. The predilection for single orderings. Journal of Abnormal \& Social Psychology, 1961, 62, 16-23.

De SOTO, C. B., \& ALBRECHT, F Conceptual good figures. In R. P. Abelson, E. Aronson, W. J. McGuire, T $M$. Newcomb, M. J. Rosenberg, and P. H. Tannenbaum (Eds.), Theories of cognitive consistency: A sourcebook. Chicago, III: Rand-McNally, 1968.

DeSOTO, C. B.., HENLEY, N. M., \& LONDON, M. Balance and the grouping schema. Joumal of Personality \& Socin Psychology, 1968, 8, 1-7

De SOTO, C. B., LONDON, M., \& HANDEL, S. Social reasoning and spatial paralogic. Journal of Personality \& Social Psycholozy, 1965, 2, 513-521.

EXLINE, R. V., ZILLER, R. C. Status congruency and interpersonal conflict in decision-making groups. Human Relations, $1959,12,147-162$.

HARARY, F., NORMAN, R. \& CARTWRIGHT, D. Structural models. New York: Wiley, 1965.

HEIDER, F. Attitudes and comitive orranization. Joumal of Psychology. 1946, 21, 107-112.

HEIDER, F. The psychology of interpersonal relations. New York: Wiley. 1958.

HENLEY, N. M., HORSFALL, R. B., \& De SOTO, C. B. Goodness of figure and social structure. Psychological Review, $1969,76,194-204$

HOMANS, G. C. Status among clerical workers. Human Organization, 1953, 12, 5-10.

HORSFALL, R. B., \& HENLEY, N. M. Mixed social structures: Strain and probability ratings. Psychonomic Science, $1969,15,186-187$.

JACKSÖN, E. F. Status consistency and symptoms of stress. American Sociolorical Review, 1962, 27, 469-479.

JORDAN, N. Behavioral forces that are a function of attitudes and of cognitive organization. Human Relations, 1953, 6. 273-287.

KASL S V \& COBB, S. Effects of parental status incongruence and discrepancy on physical and mental health of adult offspring. Joumal of Personality \& Socinl Psychology, 1967, 7 (Whole No. 642), 1-15.

KENDALL, M. G., SMITH, B. B. On the method of paired comparisons. Biometrika, 1940, 31, 324-345.

KOGAN, N.. \& TAGIURI. R. Interpersonal preference and comitive organization. Journal of Abnormal \& Social Psychology, 1958, 56, 113-116.

KUETHE, J, L., \& De SOTO, C. B. Grouping and ordering schemata in competition. Psychonomic Science, 1964, 1, 115-116.

LENSKI, G. E. Status crystallization: A non-vertical dimension of social status. American Sociological Review, 1954, 19, 405-413.

MORRISSETTE, J. O. An experimental study of the theory of structural balance. Human Relations, 1958, 11, 239-254.

MOSHER, D. L. The learning of congruent and noncongruent social structures. Journal of Social Psychology, 1967, 73 , 285-290.

WUNDERLICH, R. A., YOUNISS, J., \& De SOTO, C. B. Schemas and kinship. Psychological Reports, 1962, 11, 495-498.

ZAJONC, R. B., \& BURNSTEIN, E. The learning of balanced and unbalanced social structures. Journal of Personality, $1965,33,153-163$. NOTE

1. For more detailed and rigorous explanation of graph theory terms used in this paper, see Harary, Norman, \& Cartwright (1965). 